\title{
Student Success in Using Microfiche to Find Periodicals
}

\author{
Paul T. Adalian, Jr., \\ Ilene F. Rockman, and Ernest Rodie
}

The major purpose of this user survey was to study student usage of a microfiche serials holdings list to determine the accessibility and retrievability of periodical issues housed in four separate locations in the California Polytechnic State University Library. In-person interviews were conducted with 147 randomly selected students. Results showed that 80.6 percent of the students were successful in their searches. This dispelled the need for the library to reorganize the arrangement of periodicals.

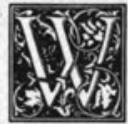

ith the rapid increase in costs for periodical subscriptions, and the unfortunate decrease in the buying power of library dollars for journals, concomitant with the dwindling physical space in which to house these journals, it comes as no surprise that within the past five years, numerous articles on periodical usage have appeared in the library literature.

These studies can be categorized into four broad areas: (1) those that count the usage of periodicals to determine selection, retention, withdrawal, shelving location (stacks or storage), and/or format (bound or microfilm) policies; ${ }^{1}(2)$ those that chronicle the actual usage of periodicals-how they are used, and by whom; ${ }^{2}(3)$ those that focus on the bibliographic retrieval skills of the users and their corresponding success and failure rates; ${ }^{3}$ and (4) those that describe "user frustrations" in accessibility and retrievability. ${ }^{4}$

Using these studies as background information, the California Polytechnic State University Library, San Luis Obispo, decided to construct its own peri- odical usage study. Rather than replicate previous projects, it was decided that a new study would be designed to enhance and expand prior research findings, as described in categories (3) and (4) above.

The Cal Poly study would emphasize the retrievability and accessibility of periodicals and was designed (1) to test the effectiveness and accuracy of a sixthousand-item computer-output-microfiche (COM) Public Serials List (PSL) on five individual microfiche cards; (2) to study the user success rate for finding, and the availability of, periodicals in four separate locations within a centralized library building -in unbound format from a closed stack Current Periodicals Department; in bound format shelved by call number in the stacks and integrated with the book collection; in an oversized stack area shelved and integrated with the book collection; and on microfilm within the centralized Reference Department; (3) to ascertain patron attitudes about the PSL system based upon ease of use, accuracy of information, readability of microfiche, and accessibility of microfiche viewers; and (4) to assess patron attitudes about the location of periodicals.

Paul T. Adalian, Jr., is head of the reference department, Ilene F. Rockman is a reference librarian in the learning resources and curriculum department, and Ernest Rodie is an M.B.A. student. All are at California Polytechnic State University, San Luis Obispo, California 93407. 


\section{HYPOTHESIS}

Several hypotheses concerning periodical usage and availability underscored the study. Numerous members of the library staff perceived that problems with the PSL format (lack of cross-references for title changes and abbreviated titles, omissions of titles held, call number errors, holding statement errors, and difficulty in discriminating between hard copy and microfilm issues) were contributing to its ineffective usage. Therefore, hypothesis one sought to test the relationship between PSL entries and user success rates for reading a periodical entry correctly without the benefit of staff assistance.

Staff members also expressed concern about the four locations of periodicals within the 200,000-square-foot, five-story library building. Consequently, hypothesis two sought to test for a relationship between the location entry on the PSL and the user's ability to correctly find the periodical in the library.

Because the library houses over 67,000 bound periodicals, close to $23,000 \mathrm{vol}-$ umes of microfilm, and approximately 2,800 current unbound titles, the significance of the study could not be underestimated.

\section{METHODOLOGY}

A face-to-face interview approach, rather than a self-reporting questionnaire, was chosen as the method of data collection. This is the traditional form of survey research, as personal interviews are the standard by which survey research has gained its credibility. ${ }^{5}$ Furthermore, the most valuable studies of catalog use have been conducted through interviews with users at the time they do the actual searching, rather than after the fact. ${ }^{6}$

The sampling frame employed in this study is a nonprobability sample of the campus population. Of the 147 interviews conducted, 144 were usable. After designing and pretesting the questionnaire, the actual administration of the instrument took place between November 8 and 19, 1982. Days and times for interviewing were selected randomly to include both heavy and light use. All interviews were conducted within the centralized Reference Department of the library by a member of the specially trained survey research committee.

The selection of subjects was randomly conducted to guard against bias. Interviewers selected the first person to approach the PSL viewer at the beginning of the interview period. Persons already at the microfiche viewers at the start of this period were disregarded. This process was repeated upon the completion of each interview. Most people approached by the interviewer agreed to participate in the study, with only a handful electing not to answer the questions. The average interview time was between five and ten minutes. This variation in time resulted from whether or not the patron was successful in searching for a periodical listing. To guard against bias and interviewer intrusion, no help was given to the patron concerning the interpretation of the listing until the completion of the questionnaire. At the conclusion of each interview, those patrons who sought to physically retrieve the periodical(s) desired were followed by the interviewer. This was done to ascertain the actual success rate of periodical retrieval within the library.

\section{RESULTS}

Characteristics of the sample are presented in tables 1 and 2. Much to the surprise of the interviewers, the largest percentage of library users (47.2 percent) were seniors in the School of Business (19.4 percent). The class level may be reflective of the fact that all students must complete a senior project before graduating from Cal Poly, although staff had assumed that lower division students enrolled in formal library instruction classes, or those who experienced point-of-use instruction by a reference librarian, might constitute a higher percentage of library users in the study. Because previous research studies had shown that business undergraduates were not frequent users of the book collection in a university library, it was unexpected that these students would be the largest group of periodical users. ?

As in the Golden, Golden, and Lenzini 
TABLE 1

\section{CHARACTERISTICS OF THE SAMPLE}

\begin{tabular}{lcr}
\hline \multicolumn{1}{c}{ Level } & Number & Percent \\
\hline Freshman & 11 & 7.6 \\
Sophomore & 20 & 13.9 \\
Junior & 32 & 22.2 \\
Senior & 68 & 47.2 \\
Graduate & 7 & 4.9 \\
Faculty & 3 & 2.1 \\
Other (visitors) & 3 & 2.1 \\
Total & 144 & 100.0 \\
\hline
\end{tabular}

TABLE 2

\section{CHARACTERISTICS OF THE SAMPLE}

\begin{tabular}{lrr}
\hline \multicolumn{1}{c}{$\begin{array}{c}\text { School } \\
\text { Affiliation }\end{array}$} & Number & Percent \\
\hline Agriculture and Natural & & \\
$\begin{array}{l}\text { Resources } \\
\text { Architecture and }\end{array}$ & 23 & \multicolumn{1}{c}{16} \\
$\quad$ Environmental Design & 7 & 4.9 \\
Business & 28 & 19.4 \\
Communicative Arts and & 25 & 17.4 \\
$\quad$ Humanities & 18 & 12.5 \\
Engineering and Technology & & \\
Human Development and & 20 & 13.9 \\
$\quad$ Education & 20 & 13.9 \\
Science and Mathematics & 3 & 2.1 \\
No affiliation & 144 & 100.0 \\
Total & & \\
\hline
\end{tabular}

studies, inferential and descriptive statistics were used to analyze the research results. Fundamental questions to be answered concerned patron success rates for matching a citation to a PSL entry, correctly reading the bibliographic holdings statement on the PSL system, and accurately retrieving the desired periodical title from any one of four locations within the 200,000-square-foot library structure.

Sources of patron's citations are shown in table 3. Reference from an index or abstract listing accounted for more than three-quarters of all the citations searched-78.5 percent. Less than 1 percent of all citations originated from a computer search printout. This fact could reflect a lack of knowledge, on the part of the sample population, of the services offered by the library in the area of automated retrieval, or simply user reliability on searching indexes and abstracts manually.

Table 4 indicates that most patrons were successful in their searches. Of the 144 total attempts, 116 ( 80.6 percent) were successful, versus only 28 (19.4 percent) un-
TABLE 3

\section{SOURCE OF CITATION}

\begin{tabular}{lrr}
\hline \multicolumn{1}{c}{ Category } & Number & Percent \\
\hline Class assignment & 4 & 2.8 \\
Reference in index/abstract & 113 & 78.5 \\
Bibliography in a journal or & & \\
$\quad$ book & 10 & 6.9 \\
Footnote in a journal or book & 3 & 2.1 \\
Computer search & 1 & .7 \\
Recommended by faculty or & 5 & 3.5 \\
$\quad$ student & 8 & 5.6 \\
Other & 144 & 100.0 \\
Total & & \\
\hline
\end{tabular}

TABLE 4

TITLE SEARCH ATTEMPTS

\begin{tabular}{lcr}
\hline & Number & Percent \\
\hline Successful & 115 & 80.00 \\
Unsuccessful & 28 & 19.40 \\
Invalid case & 1 & .60 \\
\cline { 2 - 3 } Total & 144 & 100.00 \\
\hline
\end{tabular}

successful searches for the periodical title on the PSL system.

Of these, an overwhelming 94.8 percent of the patrons were successful in determining the call number, and 78.3 percent were successful in determining the location of the periodical. This success rate is contradictory to Murfin, who noted that only 50 percent of those who used a serial directory were able to use it correctly, ${ }^{8}$ but supportive of Golden, Golden, and Lenzini, who found that 83 percent of those who used a serial card catalog were successful in locating an entry.'

Why were the Cal Poly users more successful than others in locating a periodical entry, call number, and journal in the library? Perhaps frequency of use was a factor. To test the notion that a patron who frequently uses the PSL is more proficient in locating call number and title entries than one who uses it less often, a parametric test of difference was employed with the analytic assistance of the Statistical Package of the Social Sciences (SPSS).

A t-test, a common tool for detecting significant differences between group means, was used: Table 5 summarizes the results. Group one was the group of successful patrons, and group two the unsuccessful patrons. The mean $(X)$ number of times the PSL had been previously used 
TABLE 5

PSL USAGE

\begin{tabular}{lcr}
\hline & Number of Times Used & $\mathrm{X}$ \\
\hline Successful patrons & 97 & 16 \\
Unsuccessful patrons & 22 & 15 \\
t-value $=.25, \mathrm{df}=117$ & & \\
\hline
\end{tabular}

between the two groups was similar. A value of .25 indicates that the number of times a patron uses the PSL is not a determinant of whether or not the search would be successful, which corroborates the finding of Golden, Golden, and Lenzini. $^{10}$

Looking at this hypothesis in a slightly different way, it might be expected that a patron who has never used the PSL system would have a higher rate of failure than one who had previously searched for title entries. However, when tested, there was no relationship between prior usage of the PSL and a successful search. This could reflect the fact that the PSL system is fairly easy to understand and functional even to the novice user.

Golden, Golden, and Lenzini note that another factor that might influence the success of any search is the presence of a written citation. It could be assumed that a patron who simply approaches a serials holdings list, and uses memory to recall a call number or location for a periodical title, will not be as likely to find a periodical in the library as one who has written down the citation. However, as in the Golden, Golden, and Lenzini study, no relationship existed between a written citation and the successful completion of the search.

If a patron had been referred to the PSL from another source, it could be expected that he or she might have more accurate or complete information, which could improve the chances for a successful search. When tested, it was determined that referrals had no effect on the success of a patron's search, which again supports the results of the Golden, Golden, and Lenzini study.

However, if a patron were looking for a periodical that had been previously used, it could be assumed that the chances for a successful search would be greater than in a search containing a periodical never used before. The chi-square value (9.72) indicates that a definite relationship does exist between previous uses of a periodical and a successful search. This information is displayed in table 6.

\section{TABLE 6}

PRIOR USE AND SUCCESS OF SEARCH

Entry Found Entry Not Found Total

\begin{tabular}{lccr}
\hline $\begin{array}{l}\text { Prior use of } \\
\text { periodical }\end{array}$ & $52(94.5 \%)$ & $64(71.9 \%)$ & 116 \\
No prior use & $3(5.5 \%)$ & $25(28.1 \%)$ & 28 \\
\cline { 2 - 4 } Total & 55 & 89 & 144 \\
$x^{2}=9.72$, df $=1$, sig. $=.0018$, phi $=.278$ \\
\hline
\end{tabular}

One last factor examined was the influence of prior instruction on the use of the PSL system. Of a total of 119 patrons who had used the PSL before, 81 stated that they had received some instruction, ranging from an explanation in a formal library class to simply a friend's assistance at the moment of the search. It was assumed that students with instruction would be more successful than students without instruction. However, when tested, no relationship existed between instruction and search success. This refutes the findings of Golden, Golden, and Lenzini, who found some relationship between these variables, albeit a weak one (sig. $=.07$, phi $=.09){ }^{11}$

To learn more about the causes for successful searches, six factors were tested. These were: (1) frequency of PSL use, (2) prior use of the PSL system, (3) written citation, (4) referral to the PSL, (5) prior use of the periodical, and (6) previous instruction in the use of the PSL. Only one of these factors, prior use of the periodical, contributed significantly to the successful search. However, it is possible that due to the interrelationships of all six factors, they could, taken together, influence the success of a given search more than any one single factor.

\section{LOCATING THE PERIODICAL}

Although 114 patrons were successful in locating the title of a periodical, only 91 chose to immediately find the periodical in the library. These individuals were fol- 
lowed to one of several journal locations by the interviewer to determine if they could actually find the periodical without any assistance.

The majority of search inquiries were successful-that is to say, when patrons went to the shelves for bound volumes, to the Microforms Room for microfilm reels, or to the Current Periodicals Department for unbound issues, the interviewer witnessed the successful retrieval of the journal.

For those searches that were unsuccessful, various reasons emerged. They included inaccurate location information on the PSL ( 43 percent), missing periodical issues ( 29 percent), and user errors ( 28 percent).

\section{FAILED PSL SEARCHES}

In examining the unsuccessful searches (19.4 percent), four possible reasons emerged: (1) the library did not own the periodical; (2) user error, in which the patron had an entry that was listed on the PSL but had failed to find it; (3) user error in writing the citation; and (4) PSL error, in which the needed material was owned by the library, but was either not listed on the PSL or was listed incorrectly.

\section{USER ATTITUDES}

In an attempt to learn more about user attitudes toward the PSL systems, two Likert-type, summated, even-integral rating scales were developed. On the first scale, the patron was asked to rate four attributes of the system, but only if he or she had previously used it. These attributes were (1) easy to use, (2) accuracy of information, (3) readability of microfiche, and (4) accessibility of viewers. The results of the first rating scale required no direct interpolation; however, five important points do need to be underscored: (1) no one in the sample indicated a response of "very poor," (2) there was no significant difference between successful and unsuccessful patrons, (3) no neutral position was offered as a response choice, (4) most patrons could not make a comparison between the present PSL system and any alternate choices, and (5) because some patrons had not used the PSL before, they chose not to respond to some of the interviewer's questions.

Results of the first scale show that 97 percent of all patrons who had used the PSL before found it easy to use and containing accurate information. Moreover, over three-fourths of the respondents found the information to be readable ( 80 percent), and almost all (98 percent) felt that the microfiche viewers were accessible.

The second Likert scale asked patrons to rate the present location of periodicals, if centralization would be an improvement over the current arrangement, and if a course in bibliographic instruction would be useful. This attitude scale was offered as a check on the actual usage to ascertain if any variations in responses occurred.

It is interesting to note that, although 82 percent of the respondents found periodicals in the present location to be easy to find and accessible, 86 percent felt that centralization would be an improvement over the present four locations. In addition, 88 percent felt that a library course in teaching the location of periodicals would be useful, although such a course now exists. This information would seem to indicate that, although respondents are satisfied with the current arrangement of periodicals, they still feel that there is room for location improvement.

\section{STAFF REACTIONS TO THE RESULTS}

Although the study was scientifically designed, and the methodology employed was sound according to the conventions of survey research, members of the User Survey Committee had various reactions to the research results. The committee was surprised at the high user success rate for finding title entries on the PSL. Upon checking the actual citations written on the survey instrument by the interviewer, it was learned that a majority of desired issues were periodicals indexed in The Reader's Guide to Periodical Literature. These entries were fairly straightforward, and therefore, did not include complicated forms of entry often associated with annuals, proceedings, transactions, and other serial titles. However, when the to- 
tal number of periodical titles was tallied, it was learned that titles not listed in Reader's Guide slightly outnumbered all others, despite the majority of issues emanating from the Guide. The high success rate was also questioned in light of the number of interlibrary loan (ILL) requests generated for titles and issues already owned by the library (203 out of 2,000 requests received over the past six months). In other words, if students could successfully use the PSL, why were they asking for titles already available in the library? After analyzing ILL requests, it was determined that onethird were problematic and concerned (1) association publications with no crossreferences from the title of the publication to the entry under association, (2) incomplete or incorrect holdings statements, (3) acronym titles filed at the beginning of each alphabetical sequence with no crossreference, and (4) government publications not listed on the PSL. Therefore, it was understandable that users could not successfully locate these titles. However, the staff still wondered why two-thirds of the users who had searched the PSL still could not find the desired periodical. Perhaps the users simply did not search the holdings list or, in the realm of the thousands of times the PSL had been used over the past several months, the 136 titles not found should not be viewed as a large number.

The Reference Department was surprised that no relationship was found between prior instruction in the use of the PSL and success rate for finding a title in the library. This phenomenon can be attributed to the fact that the Current Periodicals Department is located in a welltrafficked, clearly marked, and visible location in the library, and that users intuitively assumed that recent titles could be found there by virtue of the descriptive name of the department. Moreover, although respondents were successful in finding back issues of subscriptions, it seemed that most users had a misconception that all back issues could be found on microfilm, due to the proximity of the Microforms Room to the Reference Desk and to the index and abstract volumes. Therefore, it is perhaps through other factors that users were successful in locating both current and microfilm issues of desired titles.

The need to examine more rigorously these factors, or what is called the SORE (subliminal osmotic random exposure) syndrome-the ability of students to conduct successful searches by misconception and chance, enhanced by the location of relevant sources and service pointscaused the committee to further inquire into the predominant form of those journals that were found. Table 7 reports these results. By a margin of almost three to one, the most heavily used form of periodicals was microfilm. This fact does not support Murfin, who noted that the separation of microform and bound volumes resulted in user inability to locate desired volumes. ${ }^{12}$ Moreover, in the present study, of those users who did find titles on microfilm, a majority had neither previous instruction in library use nor previous experience using the PSL. Therefore, one can conclude that microfilm is not difficult to find in the library if a sound floor plan (with close proximity between abstracts and indexes, the PSL, and the Reference Service Desk) coexists with a highly visible Current Periodicals Department.

TABLE 7

FORMAT OF PERIODICALS FOUND

\begin{tabular}{lcr}
\hline & Number & Percent \\
\hline Current periodicals & 15 & 21 \\
Microfilm & 42 & 60 \\
Bound & 13 & 19 \\
\cline { 2 - 3 } Total & 70 & 100 \\
\hline
\end{tabular}

\section{CONCLUSION}

Of the 144 usable interviews conducted, 80.6 percent of the patrons sampled were successful in their searches for information using the microfiche directory, the PSL. In addition, 94.8 percent of those successful patrons were able to correctly determine the Library of Congress call number of the periodical, and 78.3 percent were able to determine correctly the location of the desired journal from one of four separate places in the library. Only one factor, prior usage of a periodical, proved to be a significant indicator of a successful 
search. The other factors-frequency of PSL use, prior use of the PSL system, a written citation, referral to the PSL from another area in the library, and prior instruction in use of the PSL-were not significant by themselves. However, it is possible that collectively they could influence the success of a search.

Of those respondents who had previously used the PSL, 97 percent found it to be easily used and to contain accurate information, with 83 percent finding that periodicals were easy to find, although located in four separate areas within the centralized library structure. When the in- terviewers followed the respondents to several periodical locations to witness the actual retrieval, 79 percent of those patrons were successful in their pursuits.

Given these findings, it appears that the PSL is an effective and accurate tool for locating periodicals, especially when the main Reference Desk is arranged near the Microforms Room, abstract and index volumes, and multiple copies of this microfiche periodicals holdings list. Therefore, the present arrangement of periodicals in four separate locations within the library will not be altered at this time.

\section{REFERENCES}

1. Julia L. Long, "Journal Use-study in a VA hospital," in Ching-Chih Chin, Quantitative Measurement and Dynamic Library Service (Phoenix, Ariz.: Oryx Pr., 1978), p.95-102; Ruth Schwartz, "A Periodical Use Study," Illinois Libraries 60:106-109 (Feb. 1978); W. M. Shaw, Jr., " A Practical Journal Usage Technique," College \& Research Libraries 39:470-84 (Nov. 1978); Sheila Newlands Testa, "Journal Use in a Community Hospital," in Quantitative Measurement and Dynamic Library Service, p.129-35.

2. Roger Flynn, "Use of Journals," in Use of Library Materials: The University of Pittsburgh Study (New York: Dekker, 1979), p.57-104.

3. Gary A. Golden, Susan U. Golden, and Rebecca T. Lenzini, "Patron Approaches to Serials: A User Study,'" College \& Research Libraries 43:22-30 (Jan. 1982).

4. Marjorie E. Murfin, "The Myth of Accessibility: Frustration and Failure in Retrieving Periodicals," Journal of Academic Librarianship 6:16-19 (Mar. 1980).

5. Charles H. Backstrom and Gerald Hursh-Cesar, Survey Research, 2d ed. (New York: Wiley, 1981).

6. F. W. Lancaster, The Measurement and Evaluation of Library Services (Washington, D.C.: Information Resources, 1977), p.20.

7. Jo Bell Whitlach, "Library Use Patterns Among Full- and Part-time Faculty and Students," College E Research Libraries 44:146 (Mar. 1983).

8. Murfin, p.18.

9. Golden, p.24.

10. Ibid., p. 25 .

11. Ibid., p. 26.

12. Murfin, p.18. 